\section{Cultural Challenges in Implementing Palliative Services in Turkey}

\author{
Rejin Kebudi, MD $^{1 *}$; Fatma Betul Cakir, MD $^{2}$ \\ ${ }^{1}$ Istanbul University Cerrahpasa Medical Faculty and Istanbul University Oncology Institute, \\ Pediatric Hematology Oncology, Istanbul, Turkey \\ ${ }^{2}$ Bezmialem Vakif University Pediatric Hematology Oncology, Istanbul, Turkey
}

\section{ABSTRACT}

\section{Special Edition 1}

Article Ref. \#: 1000PMHCOJSE1103

\section{Article History}

Received: March 6 $6^{\text {th }}, 2017$

Accepted: April 24 $4^{\text {th }}, 2017$

Published: April $24^{\text {th }}, 2017$

\section{Citation}

Kebudi R, Cakir FB. Cultural challenges in implementing palliative services in Turkey. Palliat Med Hosp Care Open J. 2017; SE(1): S10-S14. doi: 10.17140/PMHCOJ-SE-1-103

\section{Copyright}

(C)2017 Kebudi R. This is an open access article distributed under the Creative Commons Attribution 4.0 International License (CC BY 4.0), which permits unrestricted use, distribution, and reproduction in any medium, provided the original work is properly cited.
Palliative Care (PC) is a set of approaches that aims to improve physical, social and psychological well-being of both patient and the family. PC should begin at diagnosis and continue throughout treatment till the end of life. In Turkey, PC is at its infancy; the Pallia-Turk Project, to improve PC, has been implemented by the Ministry of Health since 2010. Turkish Ministry of Health has launched regulations on PC including both as a home care team and also hospitalization settlement in 2014. After these regulations, the number of PC units in Turkey has increased significantly. There is no certified PC specialization or resident program in Turkey for physicians and no certification programmes for nurses. However, PC education programs organized both by the Ministry of Health, Middle East Cancer Consortium and international and national cancer congresses by the oncology groups are encouraged in recent years. For most of the families, "palliative care" means end-of-life care. Hence, the health staff in PC, at first, should describe the mission and objective of PC both to the patients and to the families. The second most important point is that, the health care professionals should be sensitive and tolerable of various traditions or religious beliefs in order to meet the needs of patients and families and ensure a "good death" and healthy bereavement.

KEY WORDS: Palliative Care; Pallia-Turk Project; Well-being for patient and the family

ABBREVIOATIONS: WPCA: World Palliative Care Alliance; PC: Palliative Care; MECC: Middle East Cancer Consortium; DNR: Do-not-resuscitate.

\section{INTRODUCTION}

The World Health Organization (WHO) defines palliative care (PC) as an approach that improves the quality-of-life $(\mathrm{QoL})$ of patients and their families facing the problem associated with life-threatening illness, such as cancer, through the prevention and treatment of symptoms and side effects of the disease and its treatment, by means of early identification and impeccable assessment and treatment of pain and other problems, physical, psychosocial and spiritual. ${ }^{1,2}$ In a patient diagnosed with cancer, PC should begin at diagnosis and continue through treatment, follow-up care, and the end-of-life. ${ }^{1,2}$

In developed countries, PC is well developed; but in the most resource limited settings, PC services are still uncommon. The Pallia-Turk Project, to improve PC in Turkey, has been implemented by the Ministry of Health since 2010.

\section{CURRENT STATUS OF CANCER AND PALLIATIVE CARE IN TURKEY AND CULTURAL ISSUES AND CHALLENGES}

Turkey has undertaken the Health Transformation Program from 2002 on, to transfer and improve the health system and its outcomes and the situation regarding public health, insurance of the patients, and the patient satisfaction has improved in the following decade. Turkey's health 
care system has underwent radical changes since 2003 both in the provision and financing of health care services. The most important of these was the removal of different accessibility rules between social security schemes and applying the same rules to all of them. ${ }^{3,4}$ Under the General Health Insurance Scheme, all citizens are covered by the Social Security Institution. Health services are predominantly government-based managed through a social security scheme, by the Ministry of Health. When the patient has a chronic disease such as diabetes, hypertension or cancer, the patient receives full reimbursement. ${ }^{2,5}$

World Palliative Care Alliance (WPCA) like WHO, is an organization that promotes activism, monitors progresses and provides resources on education and policy to countries developing PC. WPCA in 2011 updated a global inventory of hospice and palliative care development with multiple factors and assigned the countries to six categories. ${ }^{6}$ According to this inventory, Turkey was upgraded from group II (defined as, capacity building country) in 2006 to group $3 b$ (defined as, there is generalized palliative care provisions) in $2011 .^{6}$

Turkey is a member of the Middle East Cancer Consortium (MECC), which aims to promote health care and encourages cancer education and research. MECC has been supporting the improvement of $\mathrm{PC}$ in the region by conducting various education and training programs in PC in cancer since 2004 in various Middle East countries, including Turkey., ${ }^{2,-9}$

The Turkish Ministry of Health has launched a national cancer control programme in 2009. ${ }^{10}$ The programme includes five main headings: Registry, prevention, screening and early diagnosis, treatment and palliative care. The Pallia-Turk project in this respect has been implemented by the Ministry since $2010 .{ }^{10}$ This project, focuses on implementation of a PC model with family physicians, nurses and home care teams so that patients with chronic diseases can receive basic $\mathrm{PC}$ services. This project also integrates non-government organization (NGO)s and local municipals to cover the psychosocial, economic and religious needs of the patients. The project secondarily aims new legislations for morphine prescription to increase morphine availability and to train the medical staff against "opiophobia". The project has three levels of organization: Primary, secondary and tertiary palliative care centres. In the primary level organization, family physicians and home care teams manage patients; patients who need higher level health care are referred to secondary or tertiary level centres. ${ }^{10}$ Home care teams are responsible for simple acute interventions such as pain relief, constipation, wound dressing and parenteral drug administration. In an evaluation done in 2011 , the majority of almost 40,000 patients who received home care had neurological disease $(45 \%)$, cardiovascular disease $(21 \%)$ and other chronic diseases, only $4 \%$ had cancer. ${ }^{2,5,10}$ Thus, most patients with cancer have not received home care. The number of patients receiving home care has increased significantly to 760.645 in 2016 . However, the number of cancer patients receiving home care is still inadequate. Currently, as of 2016, Turkey has 5495 physicians working in 954 home care teams. ${ }^{15}$ The Turkish Ministry of Health has launched regulations on palliative care including both as a home care team and also hospitalization settlement in $2014 .{ }^{16}$ Secondary teams include at least one physician as the head of the team educated and experienced in PC and and co-physicians, nurses, physiotherapist, nutrition expert, psychologist and social workers. Tertiary centers work in a multidisciplinary approach and include all physicians related with PC (internal medicine, surgery, medical oncology, radiation oncology, cardiology, thoracic diseases, psychiatry, physical treatment and rehabilitation, anesthesiology or algology, general practitioners), experienced oncology nurses, social workers, physiotherapists, nutrition experts, psychologists and religious people. The medical oncologist is usually the coordinator of the team. These centres also plan and take role in research and training activities of doctors, nurses and social workers and interact with NGOs and local governors. . $^{20,17,18}$ The number of PC units in Turkey has increased from 15 in 2014 to 197 in 2016; the number of beds for PC patients has increased from 179 in 2014 to 2020 in $2016 .{ }^{15}$

Although, formal PC units or team are not available in most oncology centers in Turkey, most medical and pediatric oncologists, internists, anesthetiologists and family physicians provide some form of PC in their inpatient or outpatient clinic by way of consultations with the related disciplines. Although there are some education programs on pain and other symptom control, formal comprehensive PC curriculum is not yet present. ${ }^{2,13}$ PC continuing education for residents and doctors are more satisfactorily done. During the fellowship programs of medical or pediatric oncology specialties, there is few formal PC lectures in the curriculum. However, residents and fellows mostly learn PC while caring for these oncology patients during their hospitalization. There is no certified PC specialization or resident program in Turkey. 2,13

Most nurses in medical/pediatric oncology get the experience while working in the oncology ward, from more experienced nurses and the pediatric oncologist/hematologists. In general, there are no certified PC/hospice care specialist nurses. PC in general has not been incorporated yet into the curriculum of nursing at both undergraduate and postgraduate level. ${ }^{19}$ However, PC training, for both physicians and nurses, is increasing via interdisciplinary care program in the inpatient clinics and via lectures and courses in national meetings and also in doctoral and postdoctoral curriculum., ${ }^{2,19}$ The Ministry of Health, has organized PC educations for nurses and doctors since 2010 . $^{2,5,15}$

There are perminent psychologists and psychiatrists as a part of PC only in a few oncology centers. In most centers, psychology/psychiatry consultation is requested from the related department as needed. There are few social workers, almost no art therapists employed in the oncology centers. A liason psychological support is very helpful in the centers that have the team to perform it. At pediatric setting, sometimes families do not control their feelings and may have unrealistic expectations or they may deny their children' diagnosis and/or the news of 
end of life. The families also need psychological support. Thus every center should have a permanent psychological support team. ${ }^{2}$ The medical/pediatric oncology doctors and nurses try to cover the role of the psychologist, social care worker in many centers. Although, oncologists advise and apply standard treatment protocols, they also respect patients' and their families' wishes. Mostly, it is the families rather than the patients' who participate in the decision. In pediatric cancer, the families are informed of the malignancy and the prognosis of the disease in detail, the child is informed of the malignancy in words that they may understand according to their age. Most parents do not want the doctor to tell the child that they have "cancer", and the doctor tries to convince the parents to at least use the term "tumor" in the first session. In adults, especially in the elderly, most families do not want the patient to know that he/she has cancer. ${ }^{4}$ Turkish patients suffering from cancer clearly express their desire of being told about cancer diagnosis and prognosis. ${ }^{20,21}$ However families believe that cancer is 'that is not to be named', since nothing can be done to treat it and it is always fatal. ${ }^{4,20,21}$ While this is dishonesty, it is also an expression of the individual's desire to protect a loved one from cancer - the bad news. However, the family members also deprive the patient of the right to make decisions about his or her life. ${ }^{4}$ Physicians tend to respect the patients' right to know the truth but is limited from the family pressure. $^{4,20,21}$

In a recent study, advances in technology, cancer treatment and supportive care; adequate family support and presence of governmental health insurance were reported as important factors for high levels of hope. ${ }^{20}$ Financial problems were reported to negatively affect the psychological distress and thus adversely affect the level of hope. ${ }^{22}$ Contrary to the general attitude and belief of the families in developing countries, the total hope scores of patients were found to increase with their information level about the disease. Hence, at diagnosis, family members should be convinced that the patient himself/herself should also be informed of his/her disease.

In two surveys conducted among health care professionals in Turkey, ${ }^{2}$ it was reported that the high number of patients, the limited number of staff in the healthcare team, the limited time that may be allocated to each patient, and the cultural and/ or educational background of the patient are important barriers in providing PC. The patient at terminal stage may not be hospitalized due to lack of available hospital bed. The intensive care unit (ICU) beds are also very scarce and the oncologist is confronted with the hard decision of whether to use the oncology bed or an ICU bed either for a patient who has a high chance of cure or for a dying patient. Written PC policies or guidelines should be established in each center. There is a lack of community awareness about PC in Turkey, but surveys show that volunteers for psychosocial support, mostly in pediatric oncology are somewhat more active in big cities like Istanbul, Ankara and Izmir. Some NGO voluntary groups try to give psychosocial support especially to children by organizing parties, picnics, and celebrations which are very much appreciated by the patients and the parents. They also sometimes make home visits to the patients. $^{2}$

The right of dying patients has not yet been established by law in Turkey, and do-not-resuscitate (DNR) order or practice of euthanasia for patients suffering from refractory symptoms is not legal.,23,24 End-of-life care is given mostly in the inpatient setting. Although, most of the patients or family members in rural areas prefer to stay at home at their end-of-life period, most patients in urban areas and most families of children with cancer prefer to stay in the hospital in the terminal stage, in contrary to many countries in the Middle East, where the patient or families prefer the patient to die at home where they are cared for by their family. ${ }^{2,25}$ Sending the patient home to die is frequently considered by the families as "giving up on us" and the hospital sometimes becomes more "home" for the patient than his/her own home. However, if hospice or home care were available, they could prefer it. Sometimes, families resist PC consultations because this may symbolize evidence of the patient's deterioration, which may be difficult to face. For most of the families, "palliative care" means end-of-life care; they think this kind of care will stop all the other medications about the cancer disease itself. Hence, the health staff in PC, at first, should describe the mission and objective of PC both to the patients and to the families. All cancer care must be provided respecting families' spiritual, cultural background to promote a sense of well-being and to ease suffering of the patients and the families. So health care professionals should be sensitive and tolerable of various traditions or religious beliefs in order to meet the unique spiritual needs of patients and families and ensure a "good death" and healthy bereavement. ${ }^{2}$

As a result, the patient and the family should be offered an integrated model of PC that continues throughout the course of the illness, regardless of the outcome.,26 Both regulations and legislations done by the Ministry of Health to improve the health system including PC is promising.

There is always a need of funding for the organizations necessary in the PC setting. This funding issue should be supported by the government, also the support of NGOs may be incorporated. To increase the awareness of the importance of PC in the public, thus facilitate the support of the public and NGO's the media including TV, internet (facebook, twitter) newspapers may be used.

Regarding medication for pain relief in cancer, there are regulations for prescriptions and distribution of opioids in Turkey. These are controlled by the Ministry of Health. Thus illegal use of opioids is avoided. Opioids can be prescribed by all physicians including family physicians., ${ }^{2,5,10}$ The Ministry of Health has also planned to decrease the unnecessary legislation according to European Union guidelines by 2015 and e-prescriptions, like the prescriptions of other drugs, are also planned for opioids. ${ }^{2,5}$ Since the end of 2014, slow releasing morphine is being produced in Turkey. ${ }^{15}$ 


\section{CANCER CARE TO FOREIGNERS IN TURKEY}

Multidisciplinary cancer treatment in Turkey is quite advanced in comparison to most countries in the region. Some cancer patients come from Middle East countries, Balkan countries and Turkish origin or Turkish speaking countries. There are also refugees coming to Turkey from neighboring areas of conflict. Around 3 million and 500.000 Syrians have come to Turkey since $2011 .{ }^{27}$ In addition to refugees' basic needs, the health care needs of refugees have been addressed. Refugees with cancer can be treated at tertiary government and university hospitals free of charge. In a recent study evaluating 212 refugee children with cancer, the survival outcome of these children was found to be similar to the Turkish children with cancer. ${ }^{28}$

\section{CONCLUSION}

It is essential that improved PC program should be integrated into national health-care systems to control the suffering of all adult and pediatric patients including patients with cancer. This national policy enables to develop quality standards, funding, and accessibility of adequate care for most patients and families and serves a major role in facilitating to establish the PC units/teams and education like PC curriculum and availability of essential drugs for health-care professionals. PC units/teams, hospices and home care services should be established both for adults and children. Health-care professionals should have postgraduate PC education. Governmental attempts are needed to increase the number of nurses, psychologists, psychiatrists, social workers and art therapist and in the centers. Evidence-based pain and symptom management and $\mathrm{PC}$ written guidelines should be available for the clinical use of doctors and nurses in all oncology centers. Non-govermental organizations may be incorporated in the PC efforts. The media may be used to improve the awareness of PC in the public. Government, non-govermental organizations and health care professionals should collaborate to improve PC in Turkey.

\section{CONFLICTS OF INTEREST}

The authors declare that they have no conflicts of interest.

\section{REFERENCES}

1. WHO. WHO Definition of Palliative Care. 2017. Web site. http://www.who.int/cancer/palliative/definition/en/. Accessed March 5, 2017.

2. Kebudi R, Cakir FB, Gultekin M. Palliative care to the cancer patient in Turkey. In: Silbermann M, eds. Palliative Care to the Cancer Patient: The Middle East as a Model for Emerging Countries. New York, USA: Nova Publishers; 2014.

3. Tatar M, Mollahaliloğlu S, Şahin B, Aydın S, Maresso A, Hernández-Quevedo C. Turkey: Health system review. Health Syst Transit. 2011; 13(6): 1-186.
4. Kebudi R, Cakir FB. Cancer care in a country undergoing transition: Turkey, current challenges and trends for the future. In: Silbermann M, eds: Cancer Care in Countries and Societies in Transition? New York City, USA: Springer Publishers; 2016.

5. Ozgul N, Gultekin M, Koc O, et al. Turkish community-based palliative care model: A unique design. Ann Oncol. 2012; 23(Suppl 3): 76-78. doi: 10.1093/annonc/mds093

6. Reville B, Foxwell AM. The global state of palliative care-progress and challenges in cancer care. Ann Palliat Med. 2014; 3(3): 129-138. doi: 10.3978/j.issn.2224-5820.2014.07.03

7. Middle East Cancer Consortium. Web site. http://mecc.cancer. gov. Accessed January 15, 2017.

8. Bingley AF, Clark D. Palliative Care in the Region Represented by the Middle East Cancer Consortium: A Review and Comparative Analysis. National Cancer Institute. Bethesda, MD, USA: NIH Publications; 2008: 07-6230.

9. The International observatory on end of life care MECC country reports. Web site. http://www.eolcobservatory. net/global_analysis/mecc.htm. Accessed August 17, 2008.

10. Tuncer M. National cancer program, 2009-2015, Ankara: Ministry of Health (Turkey), Department of Cancer Control [In Turkish]. 2009. Turkey: Ministry of Health publication.

11. IIS Windows Server. 2011. Web site. sbu.saglik.gov.tr. Accessed March 5, 2017.

12. Ozcelik H, Fadiloglu C, Karabulut B, Uyar M. Palliative care activity in the field of oncology in Turkey. J Palliat Care. 2010; 26(4): 305-310.

13. Komurcu S. Current status of palliative care in Turkey. $J$ Pediatr Hematol Oncol. 2011; 33(Suppl 1): S78-S80.

14. Silbermann M, Fink RM, Min SJ, et al. Evaluating Palliative Care Needs in Middle Eastern Countries. J Palliat Med. 2015;18(1): 18-25.

15. Serdar Karaca, Ministry of Health (Turkey), Department of Cancer Control; Conference in $1^{\text {st }}$ International and $4^{\text {th }}$ National Oncology Nursing Consensus Meeting. Evidence-Based Palliative Care in Cancer. Istanbul. 2017.

16. Sağlık Bakanlığından. Palyatif Bakım Hizmetlerinin Uygulama Usul ve Esasları Hakkında Yönerge [In Turkish]. Web site. http://hizmetstandartlari.saglik.gov.tr/Eklenti/2817,palyatif-bakim-hizmetleri-yonergesipdf.pdf?0. Accessed March 5, 2017.

17. Legislation for home care programs. Web site. http://saglik. gov.tr/TR/belge/1-570/evde-bakim-hizmetleri-sunumu-hakkin- 
dayonetme-lik. Accessed March 5, 2017.

18. Türkiye'de Özellikli Planlama Gerektiren Saglık Hizmetleri (Healthcare Services that need a special program in Turkey) $2011 * 2023$ (Turkish). Turkish Ministry of Health, General Directorate of Curative Services Publications, Ankara, 2011. Web site. http://www.tedavi.saglik.gov.tr/kutuphane/oplgsh.pdf. Accessed March 5, 2017.

19. Can G. Nursing education in Turkey. Nurse Educ. 2010; 35(4): 146-147. doi: 10.1097/NNE.0b013e3181e337eb

20. Kavradim ST, Ozer ZC, Bozcuk H. Hope in people with cancer: a multivariate analysis from Turkey. J Adv Nurs. 2013 May;69(5):1183-96. doi: 10.1111/j.1365-2648.2012.06110.x

21. Bozcuk H, Erdoğan V, Eken C, et al. Does awareness of diagnosis make any difference to quality of life? Determinants of emotional functioning in a group of cancer patients in Turkey. Support Care Cancer. 2002: 10: 51-57. doi: 10.1007/ s005200100308

22. Durusoy R., Karaca B, Junushova B. Uslu R. Cancer patients' satisfaction with doctors and preferences about death in a university hospital in Turkey. Patient Education Counseling 2011, 85(3): 285-290. doi: 10.1016/j.pec.2011.03.010
23. Aksoy, S. Ethical consideration on end of life issues in Turkey. In: Song KY, Koo YM, Macer DRJ, eds. Bioethics in Asia in the $21^{\text {st }}$ Century. Bangkok; Eubios Ethics Institute; 2003.

24. Oguz NY, Miles SH, Buken N, Civaner M. End of life care in Turkey. Comb $Q$ Health Ethics. 2003; 12(3): 279-284. doi: 10.1017/S0963180103123109

25. Silbermann M, Arnaout M, Abdel Rahman Sayed H, et al. Pediatric palliative care in the middle east. In: Knapp C, Madden V, Fowler-Kerry S, eds. Pediatric Palliative Care: Global Perspectives. Amterdam, The Netherlands: Springer Science+Business Media B.V.; 2012: 127-159.

26. Kebudi R. Turkish Pediatric Oncology Group. Pediatric Oncology in Turkey. J Pediatr Hematol Oncol. 2012; 34(Suppl 1): S12-4. doi: 10.1097/MPH.0b013e318249aaac

27. Türkiye'de kaç milyon mülteci var? Bakan açıkladı [In Turkish]. Web site. http://www.dha.com.tr/turkiyede-kac-milyon-multeci-var-bakan-acikladi_1457255.html. Accessed March 5, 2017.

28. Kebudi R, Bayram I, Yagci-Kupeli B, et al. Refugee children with cancer in Turkey. Lancet Oncol. 2016; 17(7): 865-867. doi: 10.1016/S1470-2045(16)30211-X 